\title{
Characteristics of perinatal depression in rural central, India: a cross-sectional study
}

\author{
Sujit D. Rathod', Simone Honikman², Charlotte Hanlon ${ }^{3,4^{*}} \mathbb{D}$ and Rahul Shidhaye ${ }^{5}$
}

\begin{abstract}
Background: Perinatal depression is associated with negative effects on child behavioural, cognitive and emotional development, birth outcomes, and physical growth. In India, increased priority accorded to mental health programs mean it is now possible to reduce the population-level burden of perinatal depression. In this secondary analysis of two studies, we aimed to describe the epidemiological features of depression among community-and facility-based samples of perinatal women from rural central India, and to describe the help-seeking behaviours from those women who screened positive for depression.

Methods: The Community Study was a multi-round population-based cross-sectional survey $(n=6087)$. The Facility Study was a multi-round facility-based cross-sectional survey $(n=1577)$. Both studies were conducted in Sehore District, Madhya Pradesh between 2013 and 2017. Field workers conducted structured interviews with perinatal women. The questionnaire had sections relating to sociodemographic characteristics, depression screening using the Patient's Health Questionnaire (PHQ9), treatment seeking for depression-related symptoms, and disability. Using data pooled from both studies, we tested each characteristic for association with the total screening score and with screening positive for depression.

Results: We identified 224 perinatal women from the Community Study and 130 perinatal women from the Facility Study, of whom $8.8 \%$ and $18.5 \%$ screened positive for depression, respectively. For the continuous PHQ9 score, there was evidence of a " $U$ " shaped association with age, and positive associations with pregnancy, disability score, suicidality and being a health facility attendee. For the binary PHQ9 score, there was evidence of positive associations with pregnancy, disability score, suicidality and being a health facility attendee.
\end{abstract}

Conclusions: This study highlights where the largest population-level variations in perinatal depression symptoms are present in this Indian sample, for which mental health service provision should be made a priority. Epidemiological evidence generated by this study, as well as new evidence on peer-delivered interventions for perinatal depression, must be utilized by policy-makers to prioritize mental health services for mothers along with maternal and child health services.

Keywords: Perinatal, Depression, Women, Epidemiology, India

\footnotetext{
*Correspondence: charlotte.hanlon@kcl.ac.uk

${ }^{4}$ Department of Psychiatry, School of Medicine, College of Health

Sciences, Addis Ababa University, Addis Ababa, Ethiopia

Full list of author information is available at the end of the article
} 


\section{Background}

Perinatal depression is defined as depression occurring in a woman while she is pregnant or within 12 months of delivery [1]. A global systematic review by Stein et al., found evidence that perinatal depression is associated with negative effects on child behavioural, cognitive and emotional development, and mixed evidence for negative effects on birth outcomes (i.e. pre-term and birth weight) and physical growth [2]. In a subsequent systematic review by Gelaye et al. of perinatal depression among low- and middle-income country (LMIC) populations there was largely consistent evidence of negative impacts for birth outcomes and physical growth [3], though insufficient evidence is available for the other impacts which were identified in the global review.

In LMIC the prevalence of antenatal depression is estimated to be $15-20 \%$, and $20 \%$ for postnatal depression [1, $3]$, though with considerable variation between countries [4-6]. Within India, prevalence estimates for antenatal or postnatal depression range between 6 and 48\% [7-15]. The high variation in estimates could be due the use of screening tools; two studies from South India which used diagnostic interviews had prevalence estimates of $11 \%$ and $16 \%[8,14]$.

From these India-based studies, a range of risk factors for perinatal depression have emerged in domains relating to sociodemographic and economic status; child gender preference; and family and marital characteristics $[7-10,13,14,16]$. Identifying women for treatment of depression has the potential to lead to direct health benefits for women and indirect benefits for their children. The need to improve child health is urgent in India, where $30 \%$ of newborns are low birth weight [17] and $38 \%$ of children under 5 are moderately or severely stunted [18].

In India, launch of the National Mental Health Policy and Mental Healthcare Act and increased priority accorded to mental health programs mean that there is now an opportunity to reduce the population-level burden of perinatal depression. To inform planning of health promotion activities and service delivery, we have characterized community- and facility-based samples of perinatal women from rural central India who were screened for depression, and described their help-seeking behaviour.

\section{Methods}

\section{Setting}

Sehore District, which is located in the central Indian state of Madhya Pradesh, has a population 1.3 million, of whom $81 \%$ live in a rural area and $68 \%$ are literate [19]. In Madhya Pradesh, maternal health services are readily accessible: $90 \%$ of mothers were immunized for tetanus prior to their last birth and $81 \%$ of births are in health facilities [20]. In collaboration with the Programme for Improving Mental Health Care (PRIME) research consortium [21], the state government started integrating mental health care services for depression into the primary health care sector, which includes perinatal health services, in Sehore District in 2013 [22]. Starting in 2016, nurses in district hospitals across the state are receiving training to detect perinatal depression and provide basic psychological interventions.

\section{Community Study}

A detailed description of the Community Study is available [23]. Briefly, the Community Study was a multiround, population-based survey which aimed to estimate the change in treatment coverage among adults (age $\geq 18$ years) affected by depression or by alcohol use disorder after implementation of PRIME. In the baseline (pre-implementation) round, research assistants selected 89 villages randomly in Sehore District, selected one voting polling station randomly from each village (range 1-5 stations), and downloaded the list of registered voters for that station from the government election commission website. At the time the study was designed, we assumed that the voter registration list was fairly comprehensive and suitable for use as a sampling frame for the population of potential health service users. After the baseline survey occurred, the implementation area was redrawn, reflecting a decision to focus programme activity on 188 villages in one sub-district. The follow up survey sample included all 188 villages, and all voter lists in each village. In both rounds, from each voting list, the research assistant selected adults randomly to recruit into the study. The baseline survey $(\mathrm{n}=3220)$ was conducted between May 2013 and March 2014, the follow-up survey $(\mathrm{n}=2914)$ was conducted between October and January 2017, and independent samples were drawn in each round.

\section{Facility Study}

The Facility Study aimed to estimate the change in detection of depression and of alcohol use disorders by primary care clinicians working in three public clinics in one sub-district of Sehore District. Research assistants recruited a systematic random sample of adults (age $\geq 18$ years) who were exiting their clinical consultations. The baseline (pre-implementation) survey $(n=760)$ was conducted between August and October 2013, the follow up (post-implementation) survey $(n=817)$ was conducted between September and October 2016, and independent samples were drawn in each round. 


\section{Data collection and measures}

In both studies, Hindi-speaking interviewers used a structured questionnaire application administered on an Android tablet device to ask participants about their sociodemographic characteristics (i.e. age, religion, caste, educational attainment, marital status, housing quality, land ownership, and parity, and age and sex of living children), and health-related status (i.e. pregnancy, depression, disability, and recent suicidal ideation). The response options for housing quality are widely understood in this setting to correspond to homes which are low quality, intermediate quality and high quality.

Interviewers screened participants for depression with the 9-item Patient's Health Questionnaire (PHQ9) [24], which has been validated in India [25]. Each item relates to a DSM-IV criterion for major depressive disorder and is scored from 0 ("not at all") to 3 ("nearly every day") with a recall period of 2 weeks. Four score categories have been established: 0-4 normal, 5-9 mild depressive symptoms, 10-14 moderate depressive symptoms $\geq 15$ moderately severe to severe depressive symptoms [26, 27]. We considered a total PHQ9 score of 10 or more to be a positive screen for depressive symptoms. A meta-analysis of PHQ9 validation studies found that this cut off score has $85 \%$ sensitivity and $89 \%$ specificity for detecting depression [28]. The Cronbach's alpha for the PHQ9 for this sample was 0.67.

To assess disability status over the past 3 months, interviewers administered the 12-item World Health Organization Disability Assessment Schedule (WHODAS) 2.0 [29], and administered an adaptation of the Composite International Diagnostic Interview (CIDI) suicidality module [30] to assess suicidal ideation in the past 12 months.

In the Community Study, interviewers asked PHQ9-positive participants whether they had sought treatment (i.e. from the specialist, generalist or complementary health provider, and the nature of the treatment). In the Facility Study, interviewers asked PHQ9-positive participants about their clinical consultation (i.e. any diagnoses made, and the nature of any advice, treatment or referral provided).

As part of the recruitment process, interviewers gave adults oral and written information about the study and participating adults affirmed their consent with a signature or thumb print. Participants who affirmatively responded to questionnaire items about suicidality received a referral to a research psychiatrist. The study protocols were approved by Sangath (Goa, India), the University of Cape Town (South Africa) and World Health Organization (Geneva, Switzerland).

\section{Statistical analysis}

For this secondary analysis, we included women from the two studies who were in the perinatal period, defined as being pregnant or had a child of 12 months or younger [1].

First, we describe the sociodemographic characteristics, health-related status and study base of participants within the Community Study, within the Facility Study, and for the pooled sample, using percentages within each category. We created tertiles of age and education. For parity, we created three categories: antenatal, postnatal with only daughters, postnatal with any sons, which was informed by previous literature about links between gender preference and depression [16]. For disability, we created tertiles of WHODAS scores to represent those with lower (score 12-15), average (16$19)$ or higher $(\geq 20)$ levels of disability.

Second, with data pooled from both studies, we evaluated whether the distribution of PHQ9 scores varied by sociodemographic characteristics, health-related status, or study base (i.e. community or facility). As the distribution of PHQ9 scores was skewed we could not use linear regression to test for associations. Instead, we report the median and interquartile range for each stratum and used the Kruskal-Wallis test to test for an association between the measure and the PHQ9 score. For the test of association between suicidal ideation and PHQ9 score, we excluded the final item on the PHQ9 from the total outcome score, as this item also pertains to suicidality. We repeated the associations analysis with a binary PHQ9 score, reported the proportion of participants in each category who screen positive (PHQ9 $\geq 10$ ), and used Fisher's exact to calculate $\mathrm{P}$ values for the differences in proportions. And then we repeated the second part of this analysis for each separate study sample.

Third, we report on the primary outcomes of the two parent studies as they pertain to this sub-sample of perinatal women. From the Community Study, we report the change, from baseline to follow-up, in the proportion of $\mathrm{PHQ}$-positive participants who reported seeking care from a health care provider for symptoms relating to depression. And from the Facility Study, we report the change from baseline to follow-up, in the proportion of PHQ9-positive participants who reported a diagnosis of depression in their clinical consultation. We tested for differences in these proportions using Fisher's exact test.

We completed all analyses in Stata SE 14.2 (College Station, TX, USA) (Stata code in Additional file 1). 


\section{Results}

In both studies, over $99 \%$ of eligible adults who were approached by field workers opted to participate in the studies. Of the 6087 Community Study and 1577 Facility Study participants, 226 and 130 women, respectively, were in the perinatal period. The sociodemographic and health-related characteristics of women in each study are described in Table 1.

In the Community Study, $28.1 \%$ of women were age $18-22$ years, $41.5 \%$ age $23-26$ years and $30.4 \%$ age 27 or more. In the Facility Study the corresponding percentages were $47.7 \%, 30.8 \%$ and $21.5 \%$, and for the pooled total sample the corresponding percentages were $35.1 \%, 37.6 \%$ and $27.1 \%$. In the community, $31.5 \%$ of perinatal women were pregnant, compared to $79.2 \%$ of women recruited from the facilities. In the total sample, few-if any-women were unmarried, owned land or participated in the rural employment programme (all $<5 \%$, data not shown). For depression screening, $8.9 \%$ of women in the community were PHQ9-positive, compared to $18.5 \%$ of women in the facilities.

The sociodemographic- and health-related factors associated with depression symptoms among participants are described in Table 2.

The pooled sample of 356 women had a median PHQ9 score of 4 (IQR 2-7), and $12.4 \%$ were PHQ9 positive. Women aged $18-22$ years had a median PHQ9 score of 5 (IQR $3-8$ ) and $16.8 \%$ were PHQ9 positive. Women aged 23-26 years had a median PHQ9 score of $3(1-6)$ and $8.1 \%$ were PHQ9 positive. Woman age 27 years had a median PHQ9 score of 4 (IQR 2-7), and $12.5 \%$ were PHQ9 positive. For the continuous PHQ9 score, there was evidence of a " $U$ " shaped association with age, and positive associations with pregnancy, disability score, suicidality and being a health facility attendee (Kruskall-Wallis $\mathrm{P}<0.05$ ). For the binary PHQ9 score, there was evidence of positive associations with pregnancy, disability score, suicidality and being a health facility attendee (Fisher's exact $\mathrm{P}<0.05$ ). The factors associated with depression symptoms for separate samples of Facility and Community Study samples are presented in Additional file 2: Table S1 and Additional file 3: Table S2.

Only 2 of 20 (10\%) of PHQ9-positive women in the Community Study reported seeking treatment for their problems, and we did not find evidence of a difference between the baseline and follow up survey rounds (Fisher's exact P > 0.05). Only 3 of 24 (12.5\%) of PHQ9positive women in the Facility Study reported a diagnosis of depression from their clinical consultation, and again we did not find evidence of a difference between baseline and follow up survey rounds (Fisher's exact $\mathrm{P}>0.05$ ).
Table 1 Sociodemographic- and health-related characteristics of perinatal women in Sehore District, India, 2013-2016

\begin{tabular}{|c|c|c|c|}
\hline & $\begin{array}{l}\text { Community } \\
\text { Study } \\
(n=224)\end{array}$ & $\begin{array}{l}\text { Facility } \\
\text { Study } \\
(n=130)\end{array}$ & Total $(n=354)$ \\
\hline \multicolumn{4}{|l|}{ Age, years } \\
\hline $18-22$ & 28.1 & 47.7 & 35.1 \\
\hline $23-26$ & 41.5 & 30.8 & 37.6 \\
\hline$\geq 27$ & 30.4 & 21.5 & 27.1 \\
\hline \multicolumn{4}{|l|}{ Education, years } \\
\hline $0-5$ & 47.8 & 25.4 & 39.6 \\
\hline $6-11$ & 39.7 & 46.9 & 42.4 \\
\hline$\geq 12$ & 12.5 & 27.7 & 18.1 \\
\hline \multicolumn{4}{|l|}{ Religion } \\
\hline Muslim & 21.0 & 29.2 & 24.0 \\
\hline Hindu & 79.0 & 70.8 & 76.0 \\
\hline \multicolumn{4}{|l|}{ Caste } \\
\hline Scheduled caste/tribe & 28.6 & 26.9 & 28.0 \\
\hline $\begin{array}{l}\text { Other backwards } \\
\text { caste }\end{array}$ & 61.6 & 60.8 & 61.3 \\
\hline General/none & 9.8 & 12.3 & 10.7 \\
\hline \multicolumn{4}{|l|}{ Housing quality } \\
\hline Low & 44.6 & 59.2 & 50.0 \\
\hline Intermediate & 21.9 & 14.6 & 19.2 \\
\hline High & 33.5 & 26.2 & 30.8 \\
\hline \multicolumn{4}{|l|}{ Currently pregnant } \\
\hline No & 68.5 & 20.8 & 50.7 \\
\hline Yes & 31.5 & 79.2 & 49.3 \\
\hline \multicolumn{4}{|l|}{ Parity } \\
\hline Primigravida & 5.4 & 30.0 & 14.4 \\
\hline Daughter(s) only & 32.6 & 24.6 & 29.7 \\
\hline$\geq 1$ son & 62.0 & 45.4 & 55.9 \\
\hline \multicolumn{4}{|l|}{ Disability level } \\
\hline Lower & 44.6 & 29.2 & 39.0 \\
\hline Average & 30.4 & 29.2 & 29.9 \\
\hline Higher & 25.0 & 41.5 & 31.1 \\
\hline \multicolumn{4}{|l|}{ Suicidal ideation ${ }^{\mathrm{a}}$} \\
\hline No & 93.8 & 94.6 & 94.1 \\
\hline Yes & 6.2 & 5.4 & 5.9 \\
\hline \multicolumn{4}{|l|}{ Depression } \\
\hline PHQ9 negative & 91.1 & 81.5 & 87.6 \\
\hline PHQ9 positive & 8.9 & 18.5 & 12.4 \\
\hline
\end{tabular}

${ }^{a}$ Measured with the CIDI suicidality module [30], with 12 months recall

\section{Discussion}

This is the first study to describe the distribution of perinatal depression in Madhya Pradesh, India, a predominantly (72\%) rural state of 72 million people. In Sehore District, we found that $8.8 \%$ of perinatal women in the community and $18.5 \%$ of women in the facility screened 
Table 2 Sociodemographic and health-related factors associated with depression symptoms among perinatal women in Sehore District, India, 2013-2016

\begin{tabular}{|c|c|c|}
\hline & $\begin{array}{l}\text { PHQ9 score, } \\
\text { median (IQR) }\end{array}$ & PHQ9 $\geq 10$ (\%) \\
\hline Total & $4(2-7)$ & 12.4 \\
\hline \multicolumn{3}{|l|}{ Age, years } \\
\hline $18-22$ & $5(3-8)$ & 16.8 \\
\hline $23-26$ & $3(1-6)$ & 8.3 \\
\hline$\geq 27$ & $4(2-7)$ & 12.5 \\
\hline \multicolumn{3}{|l|}{ Education, years } \\
\hline $0-5$ & $4(2-7)$ & 11.4 \\
\hline $6-11$ & $5(2-7)$ & 12.7 \\
\hline$\geq 12$ & $4(2-6)$ & 14.1 \\
\hline \multicolumn{3}{|l|}{ Religion } \\
\hline Muslim & $5(3-8)$ & 15.3 \\
\hline Hindu & $4(2-7)$ & 11.5 \\
\hline \multicolumn{3}{|l|}{ Caste } \\
\hline Scheduled caste/tribe & $4(2-7)$ & 10.1 \\
\hline Other backwards caste & $4(2-7)$ & 13.8 \\
\hline General/none & $4(3-6)$ & 10.5 \\
\hline \multicolumn{3}{|l|}{ Housing quality } \\
\hline Low & $4(2-7)$ & 12.4 \\
\hline Intermediate & $4(2-6)$ & 7.4 \\
\hline High & $5(2-8)$ & 15.6 \\
\hline \multicolumn{3}{|l|}{ Currently pregnant } \\
\hline No & $3(1-6)$ & 8.5 \\
\hline Yes & $5(3-8)$ & 16.9 \\
\hline \multicolumn{3}{|l|}{ Parity } \\
\hline Primigravida & $5(3-6)$ & 11.8 \\
\hline Daughter(s) only & $4(2-7)$ & 13.3 \\
\hline$\geq 1$ son & $4(2-7)$ & 12.1 \\
\hline \multicolumn{3}{|l|}{ Disability level } \\
\hline Lower & $2(1-4)$ & 1.4 \\
\hline Average & $5(3-7)$ & 11.3 \\
\hline Higher & $6(5-10)$ & 27.3 \\
\hline \multicolumn{3}{|l|}{ Suicidal ideation ${ }^{b}$} \\
\hline No & $4(2-6)^{a}$ & 10.8 \\
\hline Yes & $8(4-11)^{a}$ & 38.1 \\
\hline \multicolumn{3}{|l|}{ Study recruitment base } \\
\hline Community & $3(1-6)$ & 8.8 \\
\hline Facility & $5(3-7)$ & 18.5 \\
\hline
\end{tabular}

IQR interquartile range

Italic values indicate significance of $P$ value $(P<0.05)$

$P$ value for difference by group calculated with Kruskal-Wallis test

$P$ value for difference by group calculated with Fisher's exact

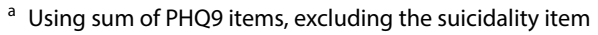

${ }^{\text {b }}$ Measured using the CIDI suicidality module [30], with 12 month recall positive for depression. Depression symptoms were common across different strata of sociodemographic and health-related characteristics. After implementation of a mental health care plan for integrated care in three subdistrict hospitals in Sehore District [22], the proportion of screen-positive women in the community who sought care did not increase, nor was there a change in clinical detection of depression among screen-positive women in facilities.

An inverse association between socioeconomic status and perinatal depression has been demonstrated in several India-based studies $[8,10,13,14,31]$ and in a global meta-analysis of socioeconomic status and depression [32]. As housing quality and education are proxies of family- and individual-level socioeconomic status, respectively, the absence of associations with depression symptoms was unexpected. It is possible that the effect of socioeconomic status on depression is relevant in areas with greater inequality. Sehore District is a rural area which is more uniformly lower-middle class; the difference between those with lower and higher quality housing is not as extreme as in other areas of India, and employment prospects for women are modest regardless of educational attainment. Future research can consider whether the association of socioeconomic status and depression-which is usually negative [32]-is modified by community-level inequality, or is equally valid in LMIC. And alternatively, future work can determine whether housing quality and education are adequate proxies for socioeconomic status in India.

Pressure to have a male child and disappointment over having a girl child were associated positively with depression symptoms from studies conducted in North, West and South India [7, 8, 10, 13, 14, 16, 33]. Male gender preference in Sehore District is evident from data which show the under- 6 sex ratio is 927 girls for every 1000 boys [19]. It is worth noting that we did not ask directly about gender preference, and instead measured a pattern of parity. Future research should directly assess women's gender preferences prior to giving birth, screen women for depression at the time of gender reveal (at birth, legally, in India), and should establish whether any change in depression symptoms associated with unmet gender preference is persistent.

Depression ultimately affects functioning, as evidenced by the association between PHQ9 and WHODAS measures observed here. It is the loss of functioning that makes depression a major contributor to the global burden of disease [34]. An explanatory model study in Goa, India shows that the idioms of distress among women with depression are primarily somatic, and help-seeking for these complaints was common [31]. As such, health promotion programmes which focus on functioning and 
somatic symptoms should consider incorporating elements of psychological counselling. For women whose disability is caused by depression, counselling directly addresses the underlying cause. For women whose disability is triggering depression symptoms, counselling confers coping skills which are likely to improve the prognosis for resolving the source of the disability.

Suicide is the second leading cause of death among young women in India [35], and in this study $5.9 \%$ of women reported suicidal ideation in the past 12 months. Commentators in India have hypothesized that suicide is not strongly linked with mental health issues in the general population [36-38]. However, limited data are available about suicide or its risk factors among perinatal women in India. Though here a statistical association was present between depression and suicidality, depression would be a poor predictor of suicide: among women who expressed suicidal ideation $72 \%$ screened negative for depression. As mental health services scale up in Madhya Pradesh, service planners must recognize that treating depression is likely to have a partial effect on reducing the level of suicidal ideation. To address the $5.9 \%$ of perinatal women who express suicidal ideation, planners must engage beyond the health sector to address determinants of suicidality which are independent of mental health problems, which as noted in a study of completed suicide among young people in South India includes factors like family conflict and domestic violence [39].

In Sehore, high levels of institutional births $(81 \%)$ and antenatal tetanus vaccination (90\%) [19] are evidence that health care across the perinatal period is available and accessible. Thus, using the maternal health infrastructure as a foundation for provision of maternal mental health care is worth considering. However, the quality of care is highly variable across publicly-funded health clinics in India, and inappropriate care could either trigger or exacerbate mental distress. Qualitative research can be used to establish where and from whom affected women prefer to receive depression services, and economic modelling can be used to estimate the cost-benefit associated with different service models.

Strengths of this analysis include the pooling of representative samples of perinatal women recruited from the communities and facilities of Sehore District, and use of a standardized screening tool. We must note some limitations of this study. As a secondary analysis of two parent studies, we had to use proxy measures which do not necessarily perfectly capture the underlying construct (i.e. housing quality for socioeconomic status, and parity for gender preference), and may explain the absence of associations. And as a sub-group analysis from a larger sample, our statistical power to detect weaker associations was limited by sample size, particularly for the change in care seeking and for change in clinical detection. In addition, the proportion of women who screen positive on the binary PHQ9 measure should be interpreted with caution. As with any screening tool, misclassification is likely. We mitigated against this misclassification by also analysing the PHQ9 score as a continuous measure. Even for the continuous measure, the Cronbach's alpha of 0.67 is a potential concern, highlighting the need to adapt a Hindi-specific screening tool for depression. Yet it is worth noting the strong association of the PHQ9 with WHODAS, which is evidence of concurrent validity. Another important limitation concerns the use of the voting registration list as a sampling frame for the Community Study. A 2018 report from the Election Commission of India [40] reveals that $61 \%$ of eligible voters in Madhya Pradesh state were registered, and that factors like pregnancy, lactation and disability make women less likely to be registered. As such, we certainly underestimated the proportion of depression screen positives in the Community Study. Further, some of the associations observed here may not be generalizable to women who were not registered to vote, as they were systematically different from voters.

\section{Conclusions}

This study highlights the key risk groups for perinatal depression-i.e. age 18-22 years, pregnant, higher disability, facility attendee-for whom mental health care should be made a priority. A recent trial demonstrated that, with training and supervision, lay health workers can deliver a manualized and adapted version of cognitive behavioural therapy to reduce depression symptoms among non-pregnant primary care attendees in India [41]. A follow up trial aims to evaluate whether peer health volunteers can do the same among pregnant women [42]; a positive result will be an impetus to promote lay counselling as a means of achieving the goals of new Mental Health Policy and Mental Healthcare Act. With adequate training and supervision, nurses and ASHA workers, who are the mainstay of national maternal and child health program in India, can be capacitated to screen vulnerable mothers and provide psychosocial interventions as indicated. In the recently published Disease Control Priorities Network, integration of mental health services into the maternal healthcare platform is recommended as being evidence-based and cost-effective [43]. Epidemiological evidence generated by this study, as well as new evidence on peerdelivered interventions for perinatal depression, must be utilized by policy-makers to prioritize mental health 
services for mothers along with maternal and child health services.

\section{Additional files}

Additional file 1. Stata do file for analysis.

Additional file 2: Table S1. Sociodemographic and health-related factors associated with depression symptoms among facility-attending perinatal women in Sehore District, India, 2013-2016.

Additional file 3: Table S2. Sociodemographic and health-related factors associated with depression symptoms among community-based perinatal women in Sehore District, India, 2013-2016.

\section{Abbreviations}

CIDI: Composite International Diagnostic Interview; DSM IV: Diagnostic and Statistical Manual of Mental Disorders 4th edition; LMIC: low-and middleincome countries; PHQ9: Patients Health Questionnaire 9-item; PRIME: Programme to Improve Mental Health Care; WHODAS: World Health Organisation Disability Assessment Schedule.

\section{Authors' contributions}

SDR made contributions to the design of the studies, analysed and interpreted the data, and was involved in drafting the manuscript. SH made contributions to the design of the studies, and was involved in drafting the manuscript. $\mathrm{CH}$ made contributions to the conception of the studies and in interpreting the data, and was involved with revising the manuscript critically. RS made contributions to the design of the studies, to acquisition and interpretation of the data, and was involved in revising the manuscript critically. All authors agree to be accountable for all aspects of the work in ensuring that questions related to the accuracy or integrity of any part of the work are appropriately investigated and resolved. All authors read and approved the final manuscript.

\section{Author details}

${ }^{1}$ Department of Population Health, London School of Hygiene \& Tropical Medicine, London, UK. ${ }^{2}$ Perinatal Mental Health Project, Alan J Flisher Centre for Public Mental Health, Department of Psychiatry and Mental Health, University of Cape Town, Cape Town, South Africa. ${ }^{3}$ Centre for Global Mental Health, Health Services and Population Research Department, Institute of Psychiatry, Psychology and Neuroscience, King's College London, London, UK. ${ }^{4}$ Department of Psychiatry, School of Medicine, College of Health Sciences, Addis Ababa University, Addis Ababa, Ethiopia. ${ }^{5}$ Public Health Foundation of India, New Delhi, India.

\section{Acknowledgements}

The authors thank Vaibhav Murhar and Dr. Sanjay Shrivastava of Sangath, India, Dr. Sandesh Samudre, Narendra Verma and Bhagwant Chilhate of the Public Health Foundation of India, and Dr. Rajeev Mohan. The authors extend our appreciation to the officials of the Department of Public Health and Family Welfare, Government of Madhya Pradesh, India.

\section{Competing interests}

The authors declare that they have no competing interests.

\section{Availability of data and materials}

The datasets used and/or analysed during the current study are available from the Principle Investigator, Rahul Shidhaye (rahul.shidhaye@phfi.org) on reasonable request.

\section{Consent for publication}

Not applicable.

\section{Ethics approval and consent to participate}

As part of the recruitment process, interviewers gave adults oral and written information about the study and participating adults affirmed their consent with a signature or thumb print. Participants who affirmatively responded to questionnaire items about suicidality received a referral to a research psychiatrist. The study protocols were approved by Sangath (Goa, India), the University of Cape Town (South Africa) and World Health Organization (Geneva, Switzerland).

\section{Funding}

This work was supported by the United Kingdom Department for International Development (Grant Number 201446). The views expressed do not necessarily reflect the UK Government's official policies. The funding body had no role in the design of the study, data collection, analysis of data, interpretation of data, or writing the manuscript.

\section{Publisher's Note}

Springer Nature remains neutral with regard to jurisdictional claims in published maps and institutional affiliations.

Received: 26 June 2018 Accepted: 3 November 2018 Published online: 12 November 2018

\section{References}

1. Fisher J, Cabral de Mello M, Patel V, Rahman A, Tran T, Holton S, et al: Prevalence and determinants of common perinatal mental disorders in women in low- and lower-middle-income countries: a systematic review. Bull World Health Organ. 2012;90:139H-49H.

2. Stein A, Pearson RM, Goodman SH, Rapa E, Rahman A, McCallum M, et al. Effects of perinatal mental disorders on the fetus and child. Lancet. 2014;384:1800-19.

3. Gelaye B, Rondon MB, Araya R, Williams MA. Epidemiology of maternal depression, risk factors, and child outcomes in low-income and middleincome countries. Lancet Psychiatry. 2016;3:973-82.

4. Klainin P, Arthur DG. Postpartum depression in Asian cultures: a literature review. Int J Nurs Stud. 2009:46:1355-73.

5. Halbreich $U$, Karkun S. Cross-cultural and social diversity of prevalence of postpartum depression and depressive symptoms. J Affect Disord. 2006;91:97-111.

6. Norhayati MN, Nik Hazlina NH, Asrenee AR, Wan Emilin WMA. Magnitude and risk factors for postpartum symptoms: a literature review. J Affect Disord. 2015;175:34-52.

7. Dubey C, Gupta N, Bhasin S, Muthal RA, Arora R. Prevalence and associated risk factors for postpartum depression in women attending a tertiary hospital, Delhi, India. Int J Soc Psychiatry. 2012;58:577-80.

8. George C, Lalitha ARN, Antony A, Kumar AV, Jacob KS. Antenatal depression in coastal South India: prevalence and risk factors in the community. Int J Soc Psychiatry. 2016;62:141-7.

9. Patel HL, Ganjiwale JD, Nimbalkar AS, Vani SN, Vasa R, Nimbalkar SM Characteristics of postpartum depression in Anand District, Gujarat, India. J Trop Pediatr. 2015;61:364-9.

10. Savarimuthu RJS, Ezhilarasu P, Charles H, Antonisamy B, Kurian S, Jacob KS. Post-partum depression in the community: a qualitative study from rural South India. Int J Soc Psychiatry. 2010;56:94-102.

11. Shivalli S, Gururaj N. Postnatal depression among rural women in South India: do socio-demographic, obstetric and pregnancy outcome have a role to play? PLoS ONE. 2015;10:e0122079.

12. Patel V, DeSouza N, Rodrigues M. Postnatal depression and infant growth and development in low income countries: a cohort study from Goa, India. Arch Dis Child. 2003:88:34-7.

13. Patel V, Rodrigues M, DeSouza N. Gender, poverty, and postnatal depression: a study of mothers in Goa, India. Am J Psychiatry. 2002;159:43-7.

14. Chandran M, Tharyan P, Muliyil J, Abraham S. Post-partum depression in a cohort of women from a rural area of Tamil Nadu, India. Incidence and risk factors. Br J Psychiatry. 2002;181:499-504.

15. Bhat A, Chowdayya R, Selvam S, Khan A, Kolts R, Srinivasan K. Maternal prenatal psychological distress and temperament in 1-4 month old infants - a study in a non-western population. Infant Behav Dev. 2015;39:35-41.

16. Shidhaye $P$, Shidhaye $R$, Phalke $V$. Association of gender disadvantage factors and gender preference with antenatal depression in women: a cross-sectional study from rural Maharashtra. Soc Psychiatry Psychiatr Epidemiol. 2017:52:737-48. 
17. United Nations. Children's Fund, World Health Organization. Low birthweight: country, regional and global estimates. New York: UNICEF; 2004

18. United Nations Development Programme. Human development report 2016: human development for everyone. New York, NY: United Nations Development Programme; 2016. http://hdr.undp.org/en/content/human -development-report-2016-human-development-everyone. Accessed 17 Aug 2017.

19. International Institute for Population Sciences. Sehore District (Madhya Pradesh) Fact Sheet. Mumbai, India: International Institute for Population Sciences; 2015. http://dhsprogram.com/pubs/pdf/OF31/MP_FactS heet_445_Sehore.pdf. Accessed 9 Nov 2018.

20. International Institute for Population Sciences. Madhya Pradesh State Fact Sheet. Mumbai, India: International Institute for Population Sciences; 2015. http://rchiips.org/NFHS/pdf/NFHS4/MP_FactSheet.pdf. Accessed 11 Oct 2017.

21. Lund C, Tomlinson M, De Silva M, Fekadu A, Shidhaye R, Jordans M, et al. PRIME: a programme to reduce the treatment gap for mental disorders in five low- and middle-income countries. PLoS Med. 2012;9:e1001359.

22. Shidhaye R, Shrivastava S, Murhar V, Samudre S, Ahuja S, Ramaswamy R, et al. Development and piloting of a plan for integrating mental health in primary care in Sehore District, Madhya Pradesh, India. Br J Psychiatry. 2016;208:s13-20.

23. Rathod SD, De Silva MJ, Ssebunnya J, Breuer E, Murhar V, Luitel NP, et al. Treatment contact coverage for probable depressive and probable alcohol use disorders in four low- and middle-income country districts: the PRIME cross-sectional community surveys. PLoS ONE. 2016;11:e0162038.

24. Kroenke K, Spitzer RL, Williams JBW. The PHQ-9: validity of a brief depression severity measure. J Gen Intern Med. 2001;16:606-13.

25. Patel V, Araya R, Chowdhary N, King M, Kirkwood B, Nayak S, et al. Detecting common mental disorders in primary care in India: a comparison of five screening questionnaires. Psychol Med. 2008:38:221-8.

26. Kroenke K, Spitzer RL, Williams JBW. The PHQ-9. Validity of a brief depression severity measure. J Gen Intern Med. 2001;46202:606-13.

27. Spitzer RL, Kroenke K, Williams JB. Validation and utility of a self-report version of PRIME-MD: the PHQ primary care study. Primary Care Evaluation of Mental Disorders. Patient Health Questionnaire. JAMA. J Am Med Assoc. 1999;282:1737-44.

28. Manea L, Gilbody S, McMillan D. Optimal cut-off score for diagnosing depression with the Patient Health Questionnaire (PHQ-9): a meta-analysis. Can Med Assoc J. 2012;184:E191-6.

29. Üstün TB, Kostanjsek N, Chatterji S, Rehm J. Measuring health and disability: manual for WHO Disability Assessment Schedule WHODAS 2.0. Geneva: World Health Organization; 2010.

30. Robins LN, Wing MD, Helzer MD, Babor TF, Burke J, Farmer MD, et al. The composite international diagnostic interview. Arch Gen Psychiatry. 1988;45:1069-77.
31. Pereira B, Andrew G, Pednekar S, Pai R, Pelto P, Patel V. The explanatory models of depression in low income countries: listening to women in India. J Affect Disord. 2007:102:209-18.

32. Lorant V, Deliege D, Eaton W, Robert A, Philippot P, Ansseau M. Socioeconomic inequalities in depression: a meta-analysis. Am J Epidemiol. 2003;157:98-112.

33. Rodrigues M, Patel $\mathrm{V}$, Jaswal S, de Souza N. Listening to mothers: qualitative studies on motherhood and depression from Goa, India. Soc Sci Med. 2003:57:1797-806.

34. Whiteford HA, Degenhardt L, Rehm J, Baxter AJ, Ferrari AJ, Erskine HE, et al. Global burden of disease attributable to mental and substance use disorders: findings from the Global Burden of Disease Study 2010. Lancet. 2013;382:1575-86.

35. Patel V, Ramasundarahettige C, Vijayakumar L, Thakur J, Gajalakshmi V, Gururaj G, et al. Suicide mortality in India: a nationally representative survey. Lancet. 2012;379:2343-51.

36. Bhise M, Behere P. Risk factors for farmers' suicides in central rural India: matched case-control psychological autopsy study. Indian J Psychol Med. 2016;38:560.

37. Dongre AR, Deshmukh PR. Farmers' suicides in the Vidarbha region of Maharashtra, India: a qualitative exploration of their causes. J Inj Violence Res. 2012;4:2-7.

38. Jacob K. Reducing suicide rates: need for public health and population interventions. Indian J Psychol Med. 2016;38:510.

39. Aaron R, Joseph A, Abraham S, Muliyil J, George K, Prasad J, et al. Suicides in young people in rural southern India. Lancet. 2004;363:1117-8.

40. Comprehensive SVEEP Plan to the State Assembly of Madhya Pradesh. Bhopal, Madhya Pradesh, India: Election Commission of India; 2018. http://ecisveep.nic.in/files/file/555-comprehensive-sveep-plan-of-madhy a-pradesh-\%E2\%80\%93-2018/. Accessed 9 Nov 2018.

41. Patel V, Weobong B, Weiss HA, Anand A, Bhat B, Katti B, et al. The Healthy Activity Program (HAP), a lay counsellor-delivered brief psychological treatment for severe depression, in primary care in India: a randomised controlled trial. Lancet. 2017;389:176-85.

42. Sikander S, Lazarus A, Bangash O, Fuhr DC, Weobong B, Krishna RN, et al. The effectiveness and cost-effectiveness of the peer-delivered Thinking Healthy Programme for perinatal depression in Pakistan and India: the SHARE study protocol for randomised controlled trials. Trials. 2015;16:534.

43. Patel V, Chisholm D, Parikh R, Charlson FJ, Degenhardt L, Dua T, et al. Addressing the burden of mental, neurological, and substance use disorders: key messages from Disease Control Priorities. Lancet. 2016:387:1672-85.
Ready to submit your research? Choose BMC and benefit from:

- fast, convenient online submission

- thorough peer review by experienced researchers in your field

- rapid publication on acceptance

- support for research data, including large and complex data types

- gold Open Access which fosters wider collaboration and increased citations

- maximum visibility for your research: over 100M website views per year

At BMC, research is always in progress.

Learn more biomedcentral.com/submissions 